\title{
Mathematical Model of a Square Waveguide Polarizer with Diaphragms
}

\author{
Andrew Bulashenko ${ }^{1}$ (D), Stepan Piltyay ${ }^{1}$ (D), Oleksandr Bulashenko ${ }^{2}$ \\ ${ }^{1}$ Department of Radio Engineering, National Technical University of Ukraine, Igor Sikorsky Kyiv Polytechnic \\ Institute,37,PeremohyAve., Kyiv,Ukraine, a.bulashenko@kpi.ua,crosspolar@ukr.net \\ ${ }^{2}$ Electromechanical Department of Ivan Kozhedub Shostka Professional College of Sumy State University, \\ InstitutskaSt., Shostka, Ukraine,ol_bulashenko@ukr.net
}

\begin{abstract}
The development of new mathematical model for guide polarization converter with diaphragms was carried out in the research by the method of wave matrices. In addition, numerical modeling of the performance of a polarizer with diaphragms is made by simulating the propagation of the fundamental modes with perpendicular linear polarizations. The wave matrix model was obtained by splitting the polarizer into separate structural elements. Each element was described by its own wave transmission matrices. As a result, a general wave scattering matrix was formed. Based on the elements this matrix the electromagnetic characteristics of the considered polarizer were obtained theoretically. In particular, complex reflection and transmission coefficients were calculated. Their modules and phases were analyzed in the frequency interval 10.7-12.8 GHz. To check the correctness of the obtained results an independent numerical simulation was carried out applying the finite element methodology in the frequency interval. The results of both approaches are in good agreement. The engineered converter of polarization with four diaphragms provides a reflection coefficient modulus of less than 0.14 and a transfer coefficient modulus of more than 0.99 for two orthogonal types of polarizations. As a result, a rigorous mathematical method was developed to analyze the elements of the scattering matrix of a waveguide polarizer with diaphragms. It can be used for the development of new broadband waveguide polarizers and waveguide filters based on diaphragm elements.
\end{abstract}

Index Terms - Electromagnetic simulation, microwave passive devices, waveguide components, polarization, waveguide polarizer, diaphragm polarizer, wave matrix, reflection coefficient, transmission coefficient.

\section{INTRODUCTION}

The fast evolution of modern communication systems in the millimeter range has contributed to the emergence and development of adaptive antenna systems with double polarization signal processing [1], [2]. The key elements of such systems are polarization transforming passive devices including orthomode converters, guide polarizers and microwave duplexers.

The polarizer of an antenna system converts linearly polarized input electromagnetic waves into circularly polarized and performs the reverse transformation. Application of this waveguide component allows to enhance the information volumes and channel's capacity in wireless telecommunication systems. Polarization processing devices have various designs based on the 
Journal of Microwaves, Optoelectronics and Electromagnetic Applications, Vol. 20, No. 4, December 2021

DOI: http://dx.doi.org/10.1590/2179-10742021v20i41368

circular or rectangular/square waveguides. The idea of constructing of polarizers is based on the introduction of a quasi-periodic or inhomogeneous structure into the waveguide that will implement a phase shift of $90^{\circ}$ between the modes with two perpendicular polarizations [3]-[8].

Historically, the first microwave devices for transformation of electromagnetic waves' polarization type were based on waveguides with reactive pins [9]-[13]. Guide structures with posts provide developers with the possibility of adjustment of charactristics. On the other hand, the main disadvantage of the polarizer designs with pins is their relatively narrow operating frequency band. Operating range of waveguide devices can be extended using ridged structures and diaphragms. Recently, new kinds of polarizers, which are based on coaxial and other waveguides with mentioned discontinuities, began to appear [14]-[20]. They provide broad frequency bands, but contain a significant number of reactive elements in the form of diaphragms. This leads to the larger overall sizes of their designs, which is their main disadvantage. Besides, several novel designs of polarizers based on structures with sectoral coaxial ridged waveguides are reported in [21]-[27]. The application of coaxial guides allows to obtain dual-band operation of antenna systems based on them.

All existent types of waveguide polarizers require the utilization of complex mathematical methods for their analysis. Among them we can highlight field-matching technique [28]-[31] and integral equations technique [32]-[34]. Consequently, creation of new easier approaches for the analysis of characteristics of waveguide polarizers is a state-of-the-art scientific and engineering problem.

In dual-band polarization processing units the polarizers are used in conjunction with orthomode transducers. An orthogonal modes converter is a guide device that discriminates two orthogonal signals with linear polarization within their common frequency range [35]-[39]. In addition, the application of waveguide filters [40]-[46] in conjunction with polarizers improves the efficiency of polarization processing of signals in antenna systems.

Diaphragm polarizers are broadly utilized in state-of-the-art satellite telecommunication systems [47]-[52]. Besides, there are effective guide polarizer designs with diaphragms and pins [53]-[58]. The main advantage of a polarizer with diaphragms over guide polarizers of other types is the ability to provide the most broadband functioning with efficient parameters, which can be upgraded by adding additional diaphragms to the design. The disadvantage is the increase in the length of the polarizer, which occurs in this case.

Diaphragm polarizers can be realized in the form of separate plates, which are placed at a certain distance from each other. They can also be realized with one specially shaped plate. Such devices are called septum polarizers [59]-[66]. The septum divides the waveguide into two rectangular waveguides. These waveguides form ports that are used to transmit or receive linearly polarized or circularly polarized waves. Such polarizers are broadly applied in state-of-the-art 5G telecommunication systems of the millimeter wavelength range [67]-[75]. The disadvantage of such guide polarizers is complex mathematical methods of their analysis. 
Therefore, the development of new mathematical model of a waveguide polarizer with diaphragms, which will allow to carry out fast analysis and optimization of its characteristics, including magnitudes and phases of the transmission and reflection coefficients, is a relevant scientific problem.

\section{THEORETICAL ANALYSIS OF WAVEGUIDE POLARIZER WITH FOUR DIAPHRAGMS}

The inner structure and overall dimensions of an investigated polarizer based on a waveguide with diaphragms are demonstrated in Fig. 1.
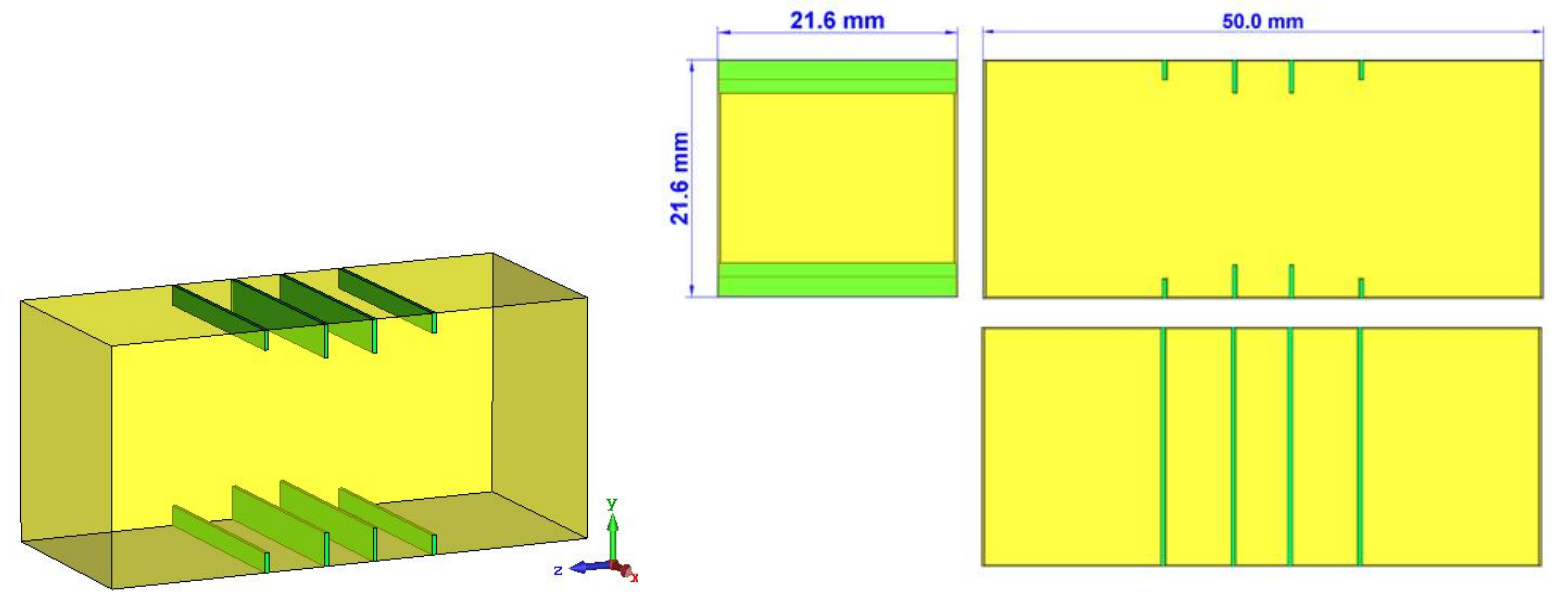

Fig. 1. The general view of a waveguide polarizer with four diaphragms.

The design of shown square guide polarizer contains four conducting diaphragms. The outer diaphragms are located symmetrically with respect to the inner diaphragms, which are located in the center of the waveguide.

For the theoretical analysis of the device we will use a single-wave approximation and the techniques of wave matrix theory [76]-[80]. The equivalent circuits of a waveguide polarizer for the case of inductive and capacitive diaphragms are given in Fig. 2.

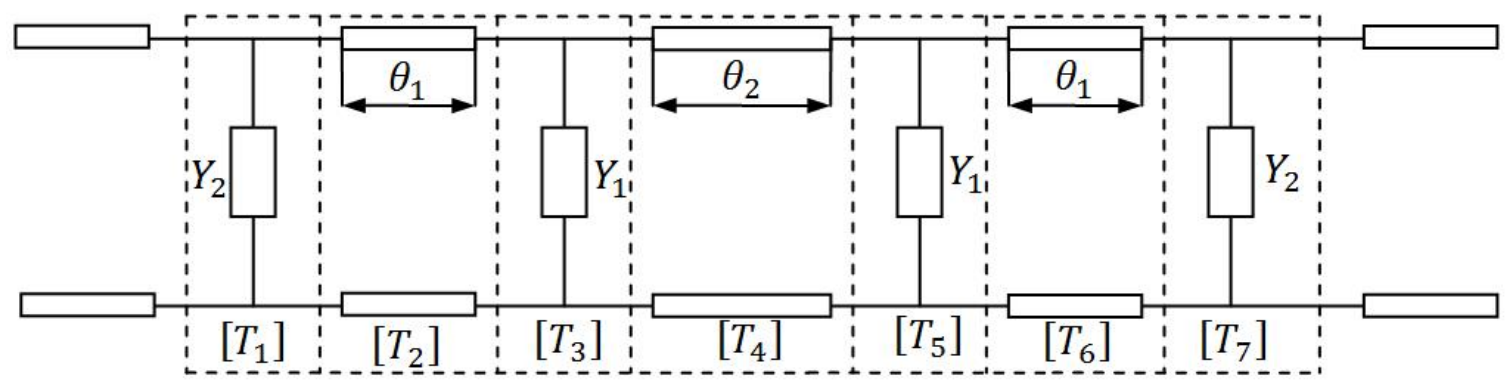

Fig. 2. Equivalent network of a waveguide polarizer with four diaphragms.

The conductivity of inductance diaphragm in the square waveguide is determined by the formula [81]

$$
\mathrm{Y}_{\mathrm{L}} \cong-j \frac{\lambda_{w}}{a} \cdot\left[\operatorname{ctg}\left(\frac{\pi d}{2 a}\right)\right]^{2}
$$

The conductivity of capacity diaphragm in the square waveguide is determined by the formula [81] 


$$
\mathrm{Y}_{\mathrm{C}} \cong j \frac{4 a}{\lambda_{w}} \cdot\left[\operatorname{cosec}\left(\frac{\pi d}{2 a}\right)\right]
$$

Where a is the size of waveguide's cross section; $d$ is the width of the gap or diaphragm window; $\lambda_{w}$ is the wavelength in a considered square guide.

Two circuits have regulatory sections of the transmission line with electrical length $\theta$, which is calculated by the formula [82]

$$
\theta \cong \frac{2 \pi l}{\lambda_{w}}
$$

where $l$ is the length of transmission line segment.

The guide wavelength is determined as follows [83]

$$
\lambda_{w} \cong \frac{\lambda_{0}}{\sqrt{1-\left(\frac{\lambda_{0}}{\lambda_{c}}\right)^{2}}}
$$

where $\lambda_{0}$ is the wavelength in vacuum, $\lambda_{c}$ is critical wavelength in the rectangular waveguide.

The equivalent circuit of a square waveguide can be divided into seven simple two-port circuits (Fig. 2). They include two circuits equivalent to outer diaphragms, two circuits equivalent to central diaphragms, two circuits of regular transmission line segments of length $l_{1}$ and circuit of a regular transmission line of length $l_{2}$. These circuits are described by transfer matrices [84]:

$$
\begin{gathered}
{\left[T_{1}\right]=\left[T_{7}\right] \cong\left[\begin{array}{ll}
T_{11} & T_{12} \\
T_{21} & T_{22}
\end{array}\right]=\left[\begin{array}{cc}
0.5\left(2+Y_{1}\right) & 0.5 Y_{1} \\
-0.5 Y_{1} & 0.5\left(2-Y_{1}\right)
\end{array}\right],} \\
{\left[T_{2}\right]=\left[T_{6}\right] \cong\left[\begin{array}{cc}
e^{j \theta_{1}} & 0 \\
0 & e^{-j \theta_{1}}
\end{array}\right],} \\
{\left[T_{3}\right]=\left[T_{5}\right] \cong\left[\begin{array}{ll}
T_{11} & T_{12} \\
T_{21} & T_{22}
\end{array}\right]=\left[\begin{array}{cc}
0.5\left(2+Y_{2}\right) & 0.5 Y_{2} \\
-0.5 Y_{2} & 0.5\left(2-Y_{2}\right)
\end{array}\right],} \\
{\left[T_{4}\right]=\left[\begin{array}{cc}
e^{j \theta_{2}} & 0 \\
0 & e^{-j \theta_{2}}
\end{array}\right]}
\end{gathered}
$$

Where $Y_{1}$ and $Y_{2}$ are conductivity of outer and middle diaphragms; $\theta_{1}$ and $\theta_{2}$ are electric length of the transmission lines.

The wave transfer matrix of the waveguide polarizer is calculated as follows [85]

$$
\left[T_{\Sigma}\right]=\left[T_{1}\right] \cdot\left[T_{2}\right] \cdot\left[T_{3}\right] \cdot\left[T_{4}\right] \cdot\left[T_{5}\right] \cdot\left[T_{6}\right] \cdot\left[T_{7}\right]=\left[\begin{array}{ll}
T_{11 . \Sigma} & T_{12 . \Sigma} \\
T_{21 . \Sigma} & T_{22 . \Sigma}
\end{array}\right]
$$

Relations between the total wave transfer and scattering matrices are determined by the known 
expressions [86], [87]

$$
\left[S_{\Sigma}\right]=\left[\begin{array}{ll}
S_{11 . \Sigma} & S_{12 . \Sigma} \\
S_{21 . \Sigma} & S_{22 . \Sigma}
\end{array}\right]=\frac{1}{T_{11 . \Sigma}}\left[\begin{array}{cc}
T_{21 . \Sigma} & |T| \\
1 & -T_{12 . \Sigma}
\end{array}\right]
$$

From (10) we obtain expressions for the reflection coefficient [88]

$$
S_{11 . \Sigma}=\frac{T_{21 . \Sigma}}{T_{11 . \Sigma}}
$$

From (10) we obtain expressions for the transmission coefficient [89]

$$
S_{21 . \Sigma}=\frac{1}{T_{11 . \Sigma}}
$$

Therefore, we will further analyze the obtained coefficients.

\section{RESUltS OF MATHEMATICAL MODELING}

The section presents the electromagnetic characteristics of the polarizer calculated using the developed model of the polarizer. The developed guide device with four diaphragms was designed for the operating frequency range from 10.7 to $12.8 \mathrm{GHz}$.

The dimensions of the optimal waveguide convertor of polarization calculated using the proposed matrix technique and the method of finite integration are as follows. The wall size of the square waveguide is $21.6 \mathrm{~mm}$. The height of the outer diaphragm is $3.91 \mathrm{~mm}$, height of the central diaphragm is $2.38 \mathrm{~mm}$. The distance between the central diaphragm is $7.38 \mathrm{~mm}$, the distance between the outer diaphragms is $7.38 \mathrm{~mm}$. The thickness of the optimal diaphragms is $1 \mathrm{~mm}$.

Frequency dependences of the module and phase of the reflection coefficients for both polarizations are presented in Fig 3a, 3b, respectively.

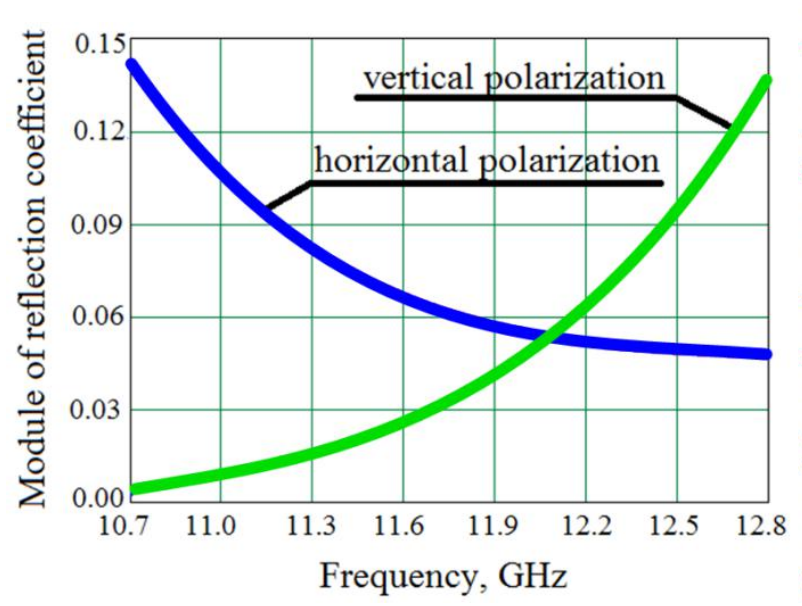

(a)

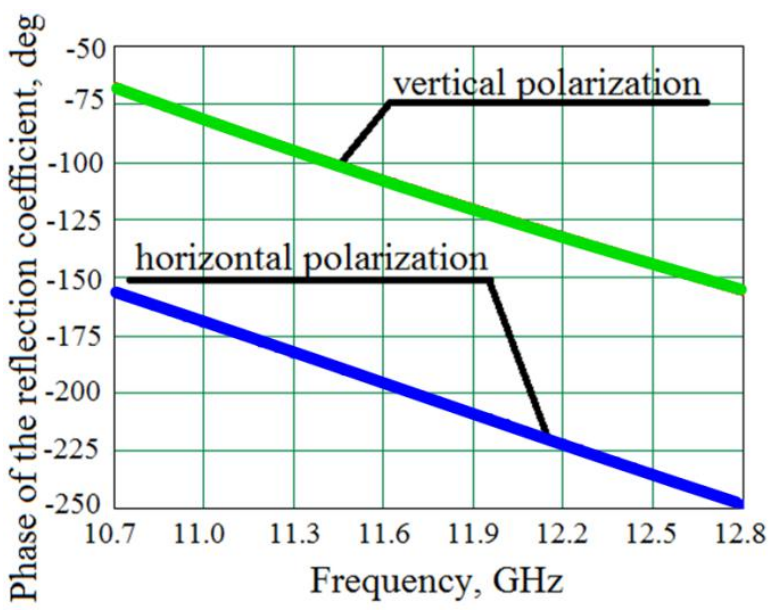

(b)

Fig. 3. Dependences of reflection coefficient on frequency for both polarizations calculated by mathematical model:

$$
\text { (a) module; (b) phase. }
$$

In Fig. 3a a typical behavior of the reflection of electromagnetic waves propagating inside a 
Journal of Microwaves, Optoelectronics and Electromagnetic Applications, Vol. 20, No. 4, December 2021 DOI: http://dx.doi.org/10.1590/2179-10742021v20i41368

polarizer's structure versus frequency is observed for both polarizations. Namely, the module of the reflection coefficient for the horizontal polarization decreases with the increment of the frequency. On the contrary, the module of the reflection coefficient of the mode with vertical polarization creases with the increase of frequency of the fundamental electromagnetic mode.

In Fig. $3 b$ it is possible to see that the phase of reflection coefficient for the vertical polarization is less $-65^{\circ}$ at a frequency of $10.7 \mathrm{GHz}$ and for the horizontal polarization it is less than $-150^{\circ}$ at the lowest frequency of $10.7 \mathrm{GHz}$.

Fig. 4 presents the dependence the module and argument of transmission coefficient on the frequency for vertical and horizontal polarization the frequency interval 10.7-12.8 GHz.

In Fig. $4 \mathrm{a}$ it is observed that the module of transmission coefficient for the horizontal polarization is higher than 0.990 at a frequency of $10.7 \mathrm{GHz}$ and for the vertical polarization is less 0.991 at a frequency of $12.8 \mathrm{GHz}$. In Fig. $4 \mathrm{~b}$ it can be seen that the phase of transmission coefficient for the vertical polarization is less $-50^{\circ}$ at a frequency of $10.7 \mathrm{GHz}$ and for the horizontal polarization is less $120^{\circ}$ at a frequency of $10.7 \mathrm{GHz}$.

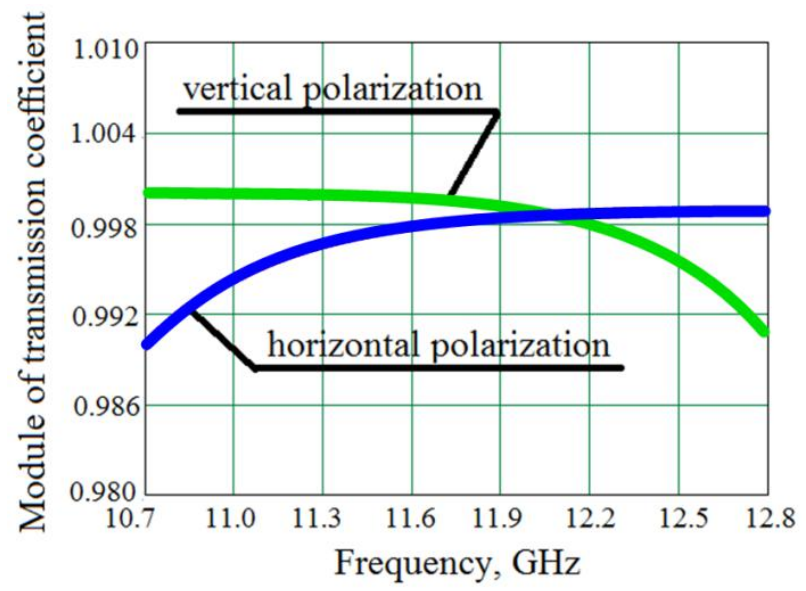

(a)

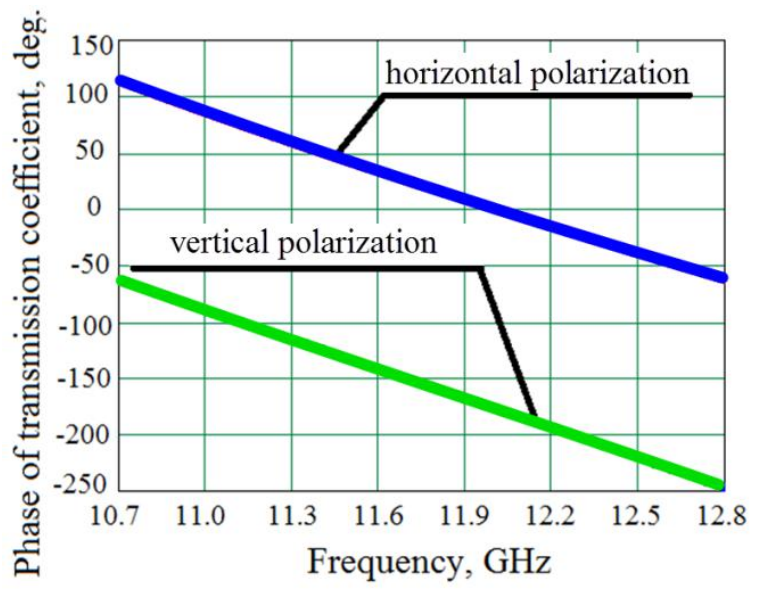

(b)

Fig. 4. Dependences of transmission coefficient on frequency for both polarizations calculated by mathematical model:

$$
\text { (a) module; (b) phase. }
$$

Consequently, in the frequency range $10.7-12.8 \mathrm{GHz}$ the optimal design of a guide polarizer with four diaphragms provides the following matching characteristics. The reflection coefficient for both polarizations is less than 0.14 . The transmission coefficient for both polarizations is greater than 0.99 .

\section{NUMERICAL SIMULATION OF THE DEVELOPED WAVEGUIDE POLARIZER}

This section contains the results of modeling a waveguide polarizer with four diaphragm applying the well-known electrodynamic method. As a proposed method we used the finite element technique in the frequency domain [90]-[92]. The electromagnetic characteristics of the polarizer were simulated for the frequency interval from 10.7 to $12.8 \mathrm{GHz}$ using the numerical method of finite elements in the frequency domain. This technique proved its computational speed and reliability for the calculation of the electromagnetic performance of waveguide polarizers in several recent investigations [93]-[96]. 
Journal of Microwaves, Optoelectronics and Electromagnetic Applications, Vol. 20, No. 4, December 2021 DOI: http://dx.doi.org/10.1590/2179-10742021v20i41368

In Fig. 5a it is possible to see that the module of the reflection coefficient of developed waveguide polarizer with diaphragms for both fundamental modes $\mathrm{TE}_{01}$ and $\mathrm{TE}_{10}$ is less than 0.11 in the frequency range 10.7-12.8 GHz. This result is in good agreement with the obtained before using wave matrix method. The minimum value of the modulus of the reflection coefficient of the polarizer is 0 at a frequency of $12.42 \mathrm{GHz}$. In Fig. $5 \mathrm{~b}$ it can be seen that the phases of reflection coefficients of both polarizations decrease with the increment of frequency. Their difference is close to $50^{\circ}$ in the whole operating frequency band $10.7-12.8 \mathrm{GHz}$.

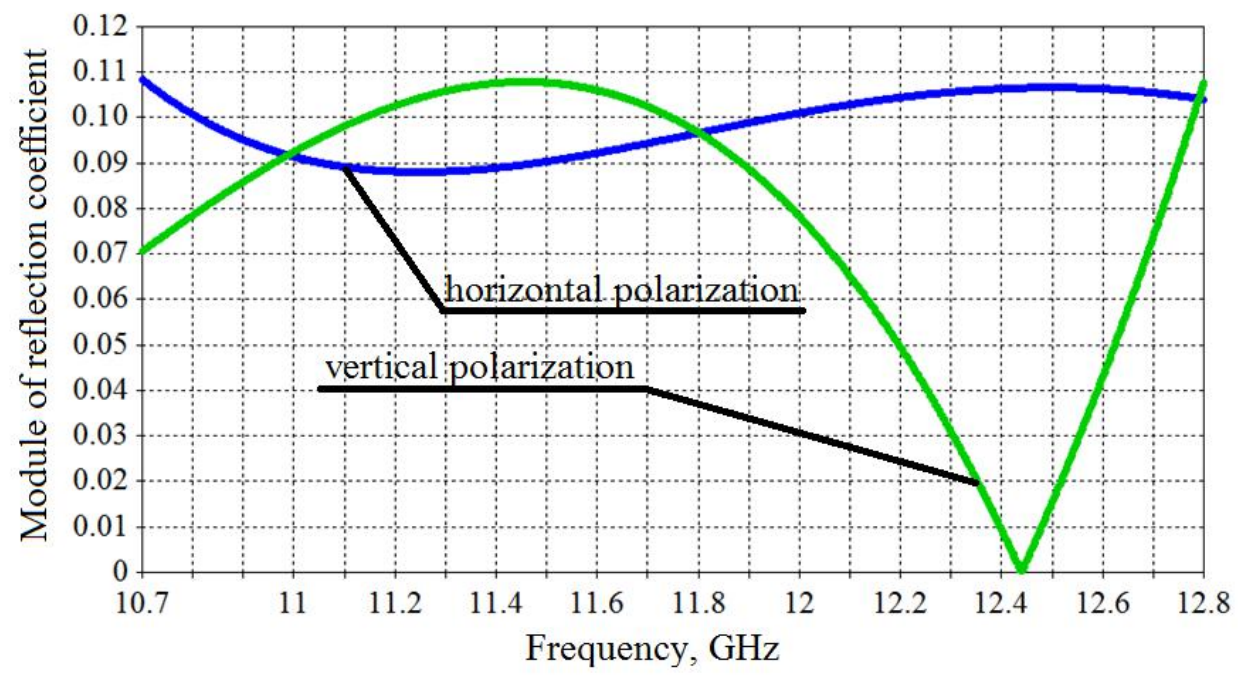

(a)



(b)

Fig. 5. Dependences of reflection coefficient on frequency for both polarizations calculated by numerical model:

(a) module; (b) phase.

In Fig. 6a it can be seen that the transmission coefficient for the vertical polarization is less than 1, which corresponds to its physical sense. The peak value is reached at the frequency of $12.44 \mathrm{GHz}$. For the horizontal polarization the transmission coefficient is less than 0.997. Its maximal value is obtained at the frequency of $11.3 \mathrm{GHz}$. 
Journal of Microwaves, Optoelectronics and Electromagnetic Applications, Vol. 20, No. 4, December 2021 DOI: http://dx.doi.org/10.1590/2179-10742021v20i41368

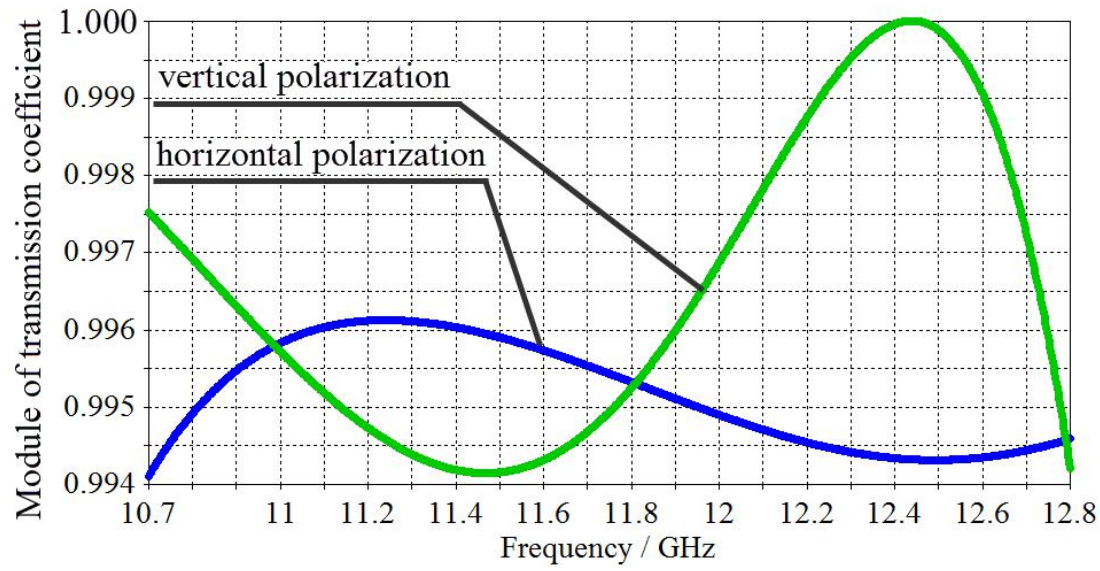

(a)

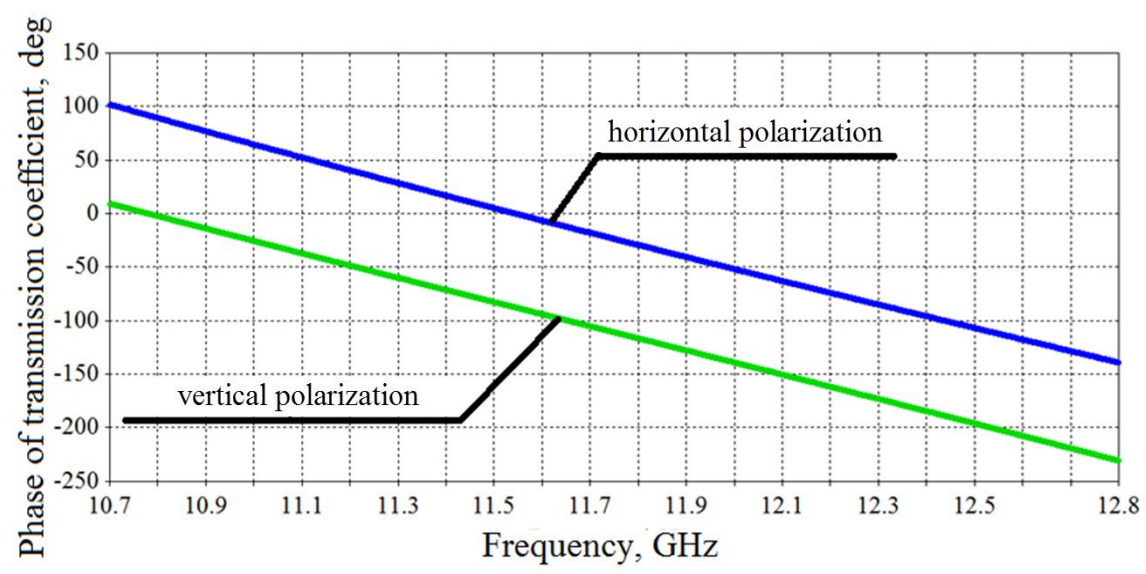

(b)

Fig. 6. Dependences of transmission coefficient on frequency for both polarizations calculated by numerical model:

(a) module; (b) phase.

In Fig. $6 \mathrm{~b}$ it is possible to see that the phase of transmission coefficient for the vertical polarization is less than $10^{\circ}$ at a frequency of $10.7 \mathrm{GHz}$ and for the horizontal polarization it is less than $100^{\circ}$ at the frequency of $10.7 \mathrm{GHz}$.

Table I presents the characteristics of the developed polarizer, which were optimized for the $\mathrm{Ku}-$ band for mathematical and numerical model. It demonstrates that the electromagnetic characteristics obtained using both the developed mathematical model and a numerical model of a waveguide polarizer with four diaphragms are in good agreement.

TABLE I. CHARACTERISTICS OF THE OPTIMIZED WAVEGUIDE POLARIZER

\begin{tabular}{lcc}
\hline \multicolumn{1}{c}{ Parameters } & Mathematical model & Numerical model \\
\hline Maximal level of reflection coefficient & 0.14 & 0.11 \\
Maximal level of transmission coefficient & 1 & 1 \\
Minimum level of transmission coefficient & 0.990 & 0.993 \\
Minimum level of phase of reflection coefficient & $-250^{\circ}$ & $-240^{\circ}$ \\
Maximal level of phase of reflection coefficient & $-65^{\circ}$ & $-75^{\circ}$ \\
Minimum level of phase of transmission coefficient & $-250^{\circ}$ & $-235^{\circ}$ \\
Maximal level of phase of transmission coefficient & $110^{\circ}$ & $100^{\circ}$ \\
\hline
\end{tabular}


Journal of Microwaves, Optoelectronics and Electromagnetic Applications, Vol. 20, No. 4, December 2021 DOI: http://dx.doi.org/10.1590/2179-10742021v20i41368

Consequently, it can be seen from Table 1 that all the parameters, which were calculated using the mathematical model and the numerical method, correlate with each other. This verifies the correctness of the created mathematical model. It can be widely applied for fast estimation of modules and arguments of the scattering parameters of polarizers, rotators, filters and other microwave devices based on discontinuities located in waveguides.

\section{CONCLUSIONS}

In this article we have developed a model of a microwave square polarizer with four diaphragms. Using the proposed model the electromagnetic parameters of a polarizer were optimized in the frequency range 10.7-12.8 GHz. The developed device ensures a reflection coefficient modulus of less than 0.14 for both linear polarization. The modulus of the transmission coefficient of a polarizer is more than 0.99 for both polarizations.

The results, which were obtained by the wave matrix model, can be used to develop and optimize waveguide polarizers with diaphragms. Further theoretical researches should focus on the creation of mathematical models for the devices with a larger number of diaphragms, which will provide better characteristics of the reflection and transmission coefficients. In addition, the presented structures can be effectively used for designing of new waveguide filters for various purposes.

\section{REFERENCES}

[1] D. M. Pozar, Microwave Engineering. Hoboken, New Jersey, USA: John Wiley and Sons, 2012.

[2] R. Sorrentino, and G. Bianchi, Microwave and RF Engineering. New Jersey, USA: John Wiley and Sons, 2010.

[3] G. Virone, R. Tascone, O. A. Peverini, G. Addamo, and R. Orta, "Combined-phase-shift waveguide polarizer", IEEE Microwave and Wireless Components Letters, vol. 18, no. 8, pp. 509-511, August 2008. DOI: 10.1109/LMWC.2008.2001005.

[4] J. A. Ruiz-Cruz, M. M. Fahmi, S. A. Fouladi, and R. R. Mansour, "Waveguide antenna feeders with integrated reconfigurable dual circular polarization", IEEE Transactions on Microwave Theory and Techniques, vol. 59, no. 12, pp. 3365-3374, December 2011. DOI: 10.1109/TMTT.2011.2170581.

[5] A. V. Bulashenko, S. I. Piltyay, and I. V. Demchenko, "Optimization of a polarizer based on a square waveguide with irises", Science-Based Technologies, vol. 47, no. 3, pp. 287-297, November 2020. (in Ukrainian). DOI: 10.18372/2310-5461.47.14878.

[6] S. Piltyay, A. Bulashenko, V. Shuliak, and O. Bulashenko, "Electromagnetic simulation of new tunable guide polarizers with diaphragms and pins", Advanced Electromagnetics, vol. 10, no. 3, 2021. DOI: 10.7716/aem.v10i3.1737.

[7] F. Dubrovka, S. Martunyuk, R. Dubrovka, M. Lytvyn, S. Lytvyn, et al., "Circularly polarised X-band H11- and H21modes antenna feed for monopulse autotracking ground station", IEEE Ukrainian Microwave Week (UkrMW), Kharkiv, Ukraine, September 2020, pp. 196-202. DOI: 10.1109/UkrMW49653.2020.9252600.

[8] F. Dubrovka, et al., "Compact X-band stepped-thickness septum polarizer", IEEE Ukrainian Microwave Week $(U k r M W)$, Kharkiv, Ukraine, September 2020, pp. 135-138. DOI: 10.1109/UkrMW49653.2020.9252583.

[9] S. Piltyay, "Circular waveguide polarizer for weather radars and satellite information systems," Journal of Microwaves, Optoelectronics and Electromagnetic Applications, vol. 20, no. 3, September 2021, pp. 475-489. DOI: 10.1590/2179$10742021 \mathrm{v} 20 \mathrm{i} 31183$.

[10] J. Roelvink and A. G. Williamson, "Three transverse cylindrical posts in a rectangular waveguide," IEEE Microwave and Wireless Components Letters, vol. 20, no. 5, pp. 253-255, May 2010. DOI: 10.1109/LMWC.2010.2045578.

[11] L. Polo-Lopez, J. L. Masa-Campos, and J. A. Ruiz-Cruz, "Design of a reconfigurable rectangular waveguide phase shifter with metallic posts," European Microwave Conf., Nuremberg, Germany, October 2017. DOI: 10.23919/EuMC.2017.8231036.

[12] S. Piltyay, A. Bulashenko, H. Kushnir, and O. Bulashenko, "Information resources economy in satellite systems based on new microwave polarizers with tunable posts," Path of Science, vol. 6, no. 11, pp. 5001-5010, 2020. DOI: 10.22178/pos.55-1.

[13] A. V. Bulashenko, S. I. Piltyay, H. S. Kushnir, and O. V. Bulashenko, "Compact waveguide polarizer with three antiphase posts," Visnyk of Vinnytsia Polytechnical Institute, no. 5, pp. 97-104, November 2020. (in Ukrainian). DOI: 10.31649/1997-9266-2020-152-5-97-104.

[14] B. Subbarao and V. F. Fusco, "Compact coaxial-fed polarizer," IEEE Antennas and Wireless Propagation Letters, vol. 3, pp. 145-147, April 2004. DOI: 10.1109/LAWP.2004.831084. 
[15] V. Shuliak et al., "Modern microwave polarizers and their electromagnetic characteristics", IEEE 3rd Ukraine Conference on Electrical and Computer Engineering, Lviv, Ukraine, August 2021, pp. 21-26.

[16] F. F. Dubrovka et al., "A novel wideband coaxial polarizer", IX International Conference on Antenna Theory and Techniques (ICATT), Odesa, Ukraine, September 2013, pp. 473-474. DOI: 10.1109/ICATT.2013.6650816.

[17] Yu. Tikhov, "Comparison of two kinds of Ka-band circular polarisers for use in a gyro-travelling wave amplifier," IET Microwaves, Antennas and Propagation, vol. 10, no. 2, pp. 147-151, January 2016. DOI: 10.1049/iet-map.2015.0292.

[18] S. I. Piltyay, "High performance extended C-band 3.4-4.8 GHz dual circular polarization feed system", XI International Conference on Antenna Theory and Techniques (ICATT), Kyiv, Ukraine, May 2017, pp. $284-287$. DOI: 10.1109/ICATT.2017.7972644.

[19] M. Bray, "Dual X/Ka-band corrugated feed horn for deep space telecommunications," Proceedings of IEEE Int. Symp. on Antennas and Propagation, Fajardo, Puerto Rico, June 2016. DOI: 10.1109/APS.2016.7696481.

[20] O. Sushko, et al., "Symmetrically fed 1-10 GHz log-periodic dipole antenna array feed for reflector antennas", IEEE Ukrainian Microwave Week (UkrMW), Kharkiv, Ukraine, September 2020, pp. 222-225. DOI: 10.1109/UkrMW49653.2020.9252778.

[21] F. F. Dubrovka et al., "Eigenmodes of sectoral coaxial ridged waveguides", Radioelectronics and Communications Systems, vol. 55, no. 6, pp. 239-247. June 2012. DOI: 10.3103/S0735272712060015.

[22] F. F. Dubrovka et al., "Prediction of eigenmodes cutoff frequencies of sectoral coaxial ridged waveguides", XI International Conference on Modern Problems of Radio Engineering, Telecommunications and Computer Science. Slavske, Ukraine, February 2012, pp. 191.

[23] L. A. Rud and K.S. Shpachenko, "Polarizers on a segment of square waveguide with diagonally ridges and adjustment iris," Radioelectronics and Communications Systems, vol. 55, no. 10, pp. 458-463, 2012. DOI: 10.3103/S0735272712100044.

[24] F. F. Dubrovka and S. I. Piltyay, "Eigenmodes of coaxial quad-ridged waveguides. Theory", Radioelectronics and Communications Systems, vol. 57, no. 1, pp. 1-30. January 2014. DOI: 10.3103/S0735272714010014.

[25] F. F. Dubrovka and S. I. Piltyay, "Eigenmodes of coaxial quad-ridged waveguides. Numerical results", Radioelectronics and Communications Systems, vol. 57, no. 2, pp. 59-69. February 2014. DOI: $10.3103 / \mathrm{S} 0735272714020010$.

[26] F. F. Dubrovka et al., "Boundary problem solution for eigenmodes in coaxial quad-ridged waveguides," Information and Telecommunication Sciences, vol. 5, no. 1, pp. 48-61. 2014.DOI: 10.20535/2411-2976.12014.48-61.

[27] S. I. Piltyay, "Numerically effective basis functions in integral equation technique for sectoral coaxial ridged waveguides", 14-th International Conference on Mathematical Methods in Electromagnetic Theory (MMET), Kyiv, Ukraine, August 2012, pp. 492-495. DOI: 10.1109/MMET.2012.6331195.

[28] J.M. Rebollar and J. Esteban, "CAD of corrugated circular-rectangular waveguide polarizers," Proceedings of Eighth Int. Conf. on Antennas and Propagation, Edinburgh, U.K., April 1993.

[29] F. F. Dubrovka and S. I. Piltyay, "Electrodynamics boundary problem solution for sectoral coaxial ridged waveguides by integral equation technique", Radioelectronics and Communications Systems, vol. 55, no. 5, pp. $191-203$. May 2012. DOI: 10.3103/S0735272712050019.

[30] M. Warecka, R. Lech, and P. Kowalczyk, "Propagation in the open cylindrical guide of arbitrary cross section with the use of field matching method," IEEE Transactions on Antennas and Propagation., vol. 66, no. 6, pp. 3237-3240, June 2018. DOI: 10.1109/TAP.2018.2819903.

[31] M. Warecka, R. Lech, and P. Kowalczyk, "Scattering and propagation analysis for the multilayered structures based on field matching technique," Proceedings of 13th European Conference on Antennas and Propagation, Krakow, Poland, April 2019

[32] H. Kushnir et al., "Multiple reflections method for diaphragms polarizers development", IEEE International Conference on Problems of Infocommunications. Science and Technology, Kharkiv, Ukraine, October 2021.

[33] F. F. Dubrovka and S. I. Piltyay, "Eigenmodes analysis of sectoral coaxial ridged waveguides by transverse fieldmatching technique. Part 1. Theory", Visnyk NTUU KPI Seriia - Radiotekhnika, Radioaparatobuduvannia, vol. 54, pp. 13-23. 2013. DOI: 10.20535/RADAP.2013.54.13-23.

[34] F. F. Dubrovka and S. I. Piltyay, "Eigenmodes analysis of sectoral coaxial ridged waveguides by transverse fieldmatching technique. Part 2. Numerical results", Visnyk NTUU KPI Seriia - Radiotekhnika, Radioaparatobuduvannia, vol. 55, pp. 13-23. 2013. DOI: 10.20535/RADAP.2013.55.13-23

[35] F. F. Dubrovka et al., "A high performance ultrawideband orthomode transducer and a dual-polarized quad-ridged horn antenna based on it", VIII International Conference on Antenna Theory and Techniques (ICATT), Kyiv, Ukraine, September 2011, pp. 176-178. DOI: 10.1109/ICATT.2011.6170737.

[36] S. I. Piltyay, "Enhanced C-band coaxial orthomode transducer", Visnyk NTUU KPI Seriia - Radiotekhnika, Radioaparatobuduvannia, vol. 58, pp. 27-34, September 2014. DOI: 10.20535/RADAP.2014.58.27-34.

[37] G. Virone, et al., "W-Band orthomode transducer for dense focal-plane clusters", IEEE Microwave and Wireless Components Letters, vol. 25, no. 2, pp. 85-87, February 2015. DOI: 10.1109/LMWC.2014.2373638.

[38] F. F. Dubrovka et al., "Novel high performance coherent dual-wideband orthomode transducer for coaxial horn feeds", XI International Conference on Antenna Theory and Techniques (ICATT), Kyiv, Ukraine, May 2017, pp. 277280. DOI: 10.1109/ICATT.2017.7972642.

[39] E. Menargues et al., "Four-port broadband orthomode transducer enabling arbitrary interelement spacing," IEEE Transactions on Microwave Theory and Techniques, vol. 66, no. 12, pp. 5521-5530, November 2018. DOI: 10.1109/TMTT.2018.2878208.

[40] M. Omelianenko and T. Romanenko, "E-plane stepped-impedance bandpass filter with wide stopband," Proceedings of IEEE 40th International Conference on Electronics and Nano technology, Kyiv, Ukraine, April 2020. DOI: 10.1109/ELNANO50318.2020.9088888. 
[41] A. Sieganschin, B. Tegowski, T. Jaschke, and A.F.Jacob, "Compact diplexers with folded circular SIW cavity filters," IEEE Transactions on Microwave Theory and Techniques, vol. 69, no. 1, pp. 111-118, Jan. 2021. DOI: 10.1109/TMTT.2020.3039545.

[42] M. Y. Omelianenko and T. V. Romanenko, "High efficiency waveguide-planar amplifier with spatial power combining for frequency range 31-39 GHz," Radioelectronics and Communications Systems, vol. 62, no. 5, pp. 195201, July 2019. DOI:10.3103/S0735272719050017.

[43] Y. Kalinichenko et al., "Adjustable iris-post waveguide polarizer for Ku-band satellite uplink systems", IEEE 3rd Ukraine Conference on Electrical and Computer Engineering, Lviv, Ukraine, August 2021, pp. 40-45.

[44] S. Piltyay, A. Bulashenko, and V. Shuliak, "Development and optimization of microwave guide polarizers using equivalent network method", Journal of Electromagnetic Waves and Applications, vol. 35, 2021. DOI: 10.1080/09205071.2021.1980913.

[45] O.Yu. Myronchuk, A. A. Shpylka, and S. Y. Zhuk, "Two-Stage method for joint estimation of information symbols and channel frequency response in OFDM communication", Radioelectronics and Communications Systems, vol. 63, pp. 418-429, October 2020. DOI: 10.3103/S073527272008004X.

[46] O. Myronchuk, O. Shpylka, and S. Zhuk, "Algorithm of channel frequency response estimation in orthogonal frequency division multiplexing systems based on Kalman filter," Proceedings of IEEE 15th Int. Conf. on Advanced Trends in Radioelectronics, Telecommunications and Computer Engineering, Lviv-Slavske, Ukraine, Feb. 2020. DOI: 10.1109/TCSET49122.2020.235385.

[47] F. F. Dubrovka, et al., "Analytical and numerical method of constructive synthesis of optimal polarizers based on three irises in square waveguide," Radioelectronics and Communications Systems, vol. 64, no 4, pp. 204-215, April 2021. DOI: $10.3103 / \mathrm{S} 073527272104004 \mathrm{X}$.

[48] V. Naydenko et al., "Evolution of radiopulses radiated by Hertz's dipole in vacuum", 12-th International Conference on Mathematical Methods in Electromagnetic Theory (MMET), Odesa, Ukraine, July 2008, pp. 294-297. DOI: 10.1109/MMET.2008.4580972.

[49] S. Piltyay, "Square waveguide polarizer with diagonally located irises for Ka-band antenna systems", Advanced Electromagnetics, vol. 10, no. 3, 2021. DOI: 10.7716/aem.v10i3.1780.

[50] S. Piltyay, A. Bulashenko, and I. Demchenko, "Compact polarizers for satellite information systems", IEEE International Conference on Problems of Infocommunications. Science and Technology (PIC S\&T), Kharkiv, Ukraine, October 2020, pp. 557-562. DOI: 10.1109/PICST51311.2020.9467889.

[51] S. I. Piltyay, O. Yu. Sushko, A. V. Bulashenko, and I. V. Demchenko, "Compact Ku-band iris polarizers for satellite telecommunication systems," Telecommunications and Radio Engineering, vol. 79, no. 19, pp. 1673-1690, December 2020. DOI: 10.1615/TelecomRadEng.v79.i19.10.

[52] S. I. Piltyay, A. V. Bulashenko, and I. V. Demchenko, "Waveguide iris polarizers for Ku-band satellite antenna feeds", Journal of Nano- and Electronic Physics, vol. 12, no. 5, pp. 05024-1-05024-5, October 2020. DOI: 10.21272/jnep.12(5).05024

[53] L. Polo-Lopez, J. L. Masa-Campos, and J. A. Ruiz-Cruz, "Design of a reconfigurable rectangular waveguide phase shifter with metallic posts," Proceedings of European Microwave Conf., Nuremberg, Germany, October 2017. DOI: 10.23919/EuMC.2017.8231036.

[54] A. V. Bulashenko, S. I. Piltyay, Y. I. Kalinichenko and O. V. Bulashenko, "Tunable square waveguide polarizer with irises and posts," Technical Engineering, vol. 86, no. 2, pp. 108-116, December 2020. (in Ukrainian). DOI: 10.26642/ten-2020-2(86)-108-116.

[55] A. Bulashenko, S. Piltyay, Y. Kalinichenko, and O. Bulashenko, "Mathematical modeling of iris-post sections for waveguide filters, phase shifters and polarizers", IEEE 2nd International Conference on Advanced Trends in Information Theory (IEEE ATIT), Kyiv, Ukraine, November 2020, pp. 330-336. DOI: $10.1109 /$ ATIT50783.2020.9349321.

[56] S. Piltyay, A. Bulashenko, H. Kushnir, and O. Bulashenko, "New tunable iris-post square waveguide polarizers for satellite information systems", IEEE 2nd International Conference on Advanced Trends in Information Theory (IEEE ATIT), Kyiv, Ukraine, November 2020, pp. 342-348. DOI: 10.1109/ATIT50783.2020.9349357.

[57] A. Chittora and S.V. Yadav, "A compact circular waveguide polarizer with higher order mode excitation", Proceedings of IEEE International Conference on Electronics, Computing and Communication Technologies, Bangalore, India, July 2020. DOI: 10.1109/CONECCT50063.2020.9198499.

[58] I. I. Dikhtyaruk et al., "Technique of mathematical synthesis of waveguide iris polarizers", Journal of Nano- and Electronic Physics, vol. 13, no. 5, pp. 05021-1-05021-5, 2021.

[59] A. V. Bulashenko, S. I. Piltyay, Y. I. Kalinichenko, and I. V. Zabegalov, "Waveguide polarizer for radar and satellite systems”, Visnyk NTUU KPI Seriia - Radiotekhnika Radioaparatobuduvannia, vol. 86, September 2021, pp. 5-13. DOI: 10.20535/RADAP.2021.86.5-13.

[60] K. Schraml and D. Heberling, "Study on perturbations in a tracking radar using septum polarizers for integration of a second antenna system," Proceedings of Loughborough Antennas \& Propagation Conference, Loughborough, U.K., Nov. 2018. DOI: $10.49 / \mathrm{cp} .2018 .1466$.

[61] N. Nikolic, A. Weily, I. Kekic, S. L. Smith, and K.W. Smart, "A septum polarizers with integrated square to circular tapered waveguide transition," Proceedings of IEEE International Symposium on Antennas and Propagation \& USNC/URSI National Radio Science Meeting, Boston, USA, July 2018. DOI: 10.1109/APUSNCURSINRSM.2018.8608909.

[62] F. F. Dubrovka et al., "Optimum septum polarizer design for various fractional bandwidths," Radioelectronics and Communications Systems, vol. 63, no. 1, pp. 15-23, January 2020. DOI: 10.3103/S0735272720010021.

[63] I. V. Demchenko et al., "Wave matrix technique for waveguide iris polarizers simulation. Numerical results", Journal of Nano- and Electronic Physics, vol. 13, no. 5, pp. 05017-1-05017-5, 2021. 
[64] F. Dubrovka, et. al., "Compact X-band stepped-thickness septum polarizer," Proceedings of IEEE Ukrainian Microwave Week, Kharkiv, Ukraine, September 2020, pp. 135-138. DOI: 10.1109/UkrMW49653.2020.9252583.

[65] F. Dubrovka et al., "Circularly polarised X-band H11- and H21-modes antenna feed for monopulse autotracking ground station”, IEEE Ukrainian Microwave Week (UkrMW), Kharkiv, Ukraine, September 2020, pp. 196-202. DOI: 10.1109/UkrMW49653.2020.9252600.

[66] Z. Ding, R. Jin, S. Yang, and X. Zhu, "Design of septum waveguide feed manufactured by split-block technique," Proceedings of IEEE International Sumposium on Antennas and Propagation and North American Radio Science Meeting, Montreal, Canada, July 2020. DOI: 10.1109/IEEECONF35879.2020.9330045.

[67] C. Shu, J. Wang, and X. Chen, "A wideband dual-circular-polarization horn antenna for mmWave wireless communications," IEEE Antennas and Wireless Propagation Letters, vol. 18, no. 9, pp. 1726-1730, September 2019. DOI: 10.1109/LAWP.2019.2927933.

[68] Y.-X. Zhang, Y.-C. Jiao, and L. Zhang, "Wideband inhomogeneous-polarizer loaded polarized SIW horn antennas for broadband millimeter-wave applications," IEEE Antennas and Wireless Propagation Letters, vol. 18, no. 7, pp. 14481452, July 2019. DOI: 10.1109/LAWP.2019.2919636.

[69] K. Al-Amoodi, et al., "A compact substrate integrated waveguide notched-septum polarizer for 5G mobile devices," IEEE Antennas and Wireless Propagation Letters, vol. 19, no. 12, pp. 2517-2521, December 2020. DOI: 10.1109/LAWP.2020.3038404.

[70] A.V. Bulashenko, "Evaluation of D2D Communications in $5 \mathrm{G}$ networks," Visnyk NTUU KPI Seriia - Radiotekhnika, Radioaparatobuduvannia, vol. 81, pp. 21-29, June 2020 (in Ukrainian). DOI: 10.20535/RADAP.2020.81.21-29.

[71] A. Bulashenko, S. Piltyay, A. Polishchuk, and O. Bulashenko, "New traffic model of M2M Technology in 5G wireless sensor networks", IEEE 2nd International Conference on Advanced Trends in Information Theory (IEEE ATIT), Kyiv, Ukraine, November 2020, pp. 125-131.DOI: 10.1109/ATIT50783.2020.9349305.

[72] S. Piltyay, A. Bulashenko, and I. Demchenko, "Wireless sensor network connectivity in heterogeneous 5G mobile systems", IEEE International Conference on Problems of Infocommunications. Science and Technology (PIC S\&T), Kharkiv, Ukraine, October 2020, pp. 625-630. DOI: 10.1109/PICST51311.2020.9468073.

[73] A. Bulashenko, S. Piltyay, and I. Demchenko, "Energy efficiency of the D2D direct connection system in 5G networks", IEEE International Conference on Problems of Infocommunications. Science and Technology (PIC S\&T), Kharkiv, Ukraine, October 2020, pp. 537-542. DOI: 10.1109/PICST51311.2020.9468035.

[74] J.L. Cano and A. Mediavilla, "On the accurate full characterizations of septum polarizer through simple amplitude measurements in black-to-back configuration," IEEE Transactions on Microwave Theory and Techniques, vol. 69, no. 1, pp. 179-188, January 2020. DOI: 10.1109/TMTT.2020.3020639.

[75] C. Shu, S. Hu, X. Chen and Y. Yao, "Deep-learning-based inverse modeling with CMA-ES as applied to the design of a wideband high-isolation septum polarizer," Proceedings of IEEE International Sumposium on Antennas and Propagation and North American Radio Science Meeting, Montreal, Canada, July 2020. DOI: 10.1109/IEEECONF35879.2020.9330082.

[76] A. Bulashenko, S. Piltyay, and I. Demchenko, "Analytical technique for iris polarizers development", IEEE International Conference on Problems of Infocommunications. Science and Technology (PIC S\&T), Kharkiv, Ukraine, October 2020, pp. 593-598. DOI: 10.1109/PICST51311.2020.9467981.

[77] S. I. Piltyay, A. V. Bulashenko, and I. V. Demchenko, "Analytical synthesis of waveguide iris polarizers", Telecommunications and Radio Engineering, vol. 79, no. 18, pp. 1579-1597, November 2020. DOI: 10.1615/TelecomRadEng.v79.i18.10.

[78] A. V. Bulashenko and S. I. Piltyay, "Equivalent microwave circuit technique for waveguide iris polarizers development", Visnyk NTUU KPI Seriia - Radiotekhnika, Radioaparatobuduvannia, vol. 83, pp. 17-28, December 2020. DOI: 10.20535/RADAP.2020.83.17-28.

[79] A. V. Bulashenko, S. I. Piltyay, and I. V. Demchenko, "Wave matrix technique for waveguide iris polarizers simulation. Theory", Journal of Nano- and Electronic Physics, vol. 12, no. 6, pp. 06026-1-06026-5, December 2020. DOI: 10.21272/jnep.12(6).06026.

[80] S. Piltyay, A. Bulashenko, I. Fesyuk, and O. Bulashenko, "Comparative analysis of compact satellite polarizers based on a guide with diaphragms", Advanced Electromagnetics, vol. 10, no. 2, pp. 44-55, July 2021. DOI: 10.7716/aem.v10i2.1713.

[81] L. Lewin, Theory of Waveguides: Techniques for the Solution of Waveguide Problems. London, U.K.: NewnesButterworth, 1975.

[82] J. Dobrowolski, Scattering parameters in RF and microwave circuit analysis and design. Norwood, USA: Artech House, 2016

[83] W. L. Stutzman, Polarization in Electromagnetic Systems. Norwood, MA, USA: Artech House, 2018.

[84] P.J. Clarricoats and A.D. Olver, Corrugate Horn Antennas. London, U.K.: Peter Peregrinus, 1984, 484 p.

[85] K. Kurokawa, An introduction to the theory of microwave circuits. New Jersey, USA: Murray Hill, 1969.

[86] I. Bahl, Lumped elements for RF and microwave circuits. Norwood, USA: Artech House, 2003.

[87] M. Golio, J. Golio, RF and microwave circuits, measurments, and modeling. New York, USA: Taylor \& Francis Group, 2007, 774p.

[88] Y.B. Siddik, Design of ultra wideband power transfer networks. New York, USA: John Wiley \& Sons, 2010, 774p.

[89] R. Ludwig, P. Bretchko, RF Circuit design: theory and applications. New Jersey, USA: Prentice Hall, 2000, 653p.

[90] S. Piltyay, A. Bulashenko, Ye. Herhil, and O. Bulashenko, "FDTD and FEM simulation of microwave waveguide polarizers", IEEE 2nd International Conference on Advanced Trends in Information Theory (IEEE ATIT), Kyiv, Ukraine, November 2020, pp. 357-363.DOI: 10.1109/ATIT50783.2020.9349339. 
Journal of Microwaves, Optoelectronics and Electromagnetic Applications, Vol. 20, No. 4, December 2021

DOI: http://dx.doi.org/10.1590/2179-10742021v20i41368

[91] S. I. Piltyay et al., "Numerical performance of FEM and FDTD methods for the simulation of waveguide polarizers", Visnyk NTUU KPI Seriia - Radiotekhnika Radioaparatobuduvannia, vol. 84, pp. 11-21. March 2021. DOI: 10.20535/RADAP.2021.84.11-21.

[92] S. Piltyay, A. Bulashenko, et al., "Analytical modeling and optimization of new Ku-band tunable square waveguide iris-post polarizer", International Journal of Numerical Modelling: Electronic Network, Devices and Fields, vol. 34, no. 5, pp. 1-27, 2021. DOI: 10.1002/JNM.2890.

[93] I. Fesyuk et al., "Waveguide polarizer for radar systems of $2 \mathrm{~cm}$ wavelength range", IEEE 3rd Ukraine Conference on Electrical and Computer Engineering, Lviv, Ukraine, August 2021, pp. 15-20.

[94] O. Bykovskyi et al., "Synthesis of waveguide diaphragm polarizers using wave matrix approach", IEEE 3rd Ukraine Conference on Electrical and Computer Engineering, Lviv, Ukraine, August 2021, pp. 111-116.

[95] Y. Herhil et al., "Characteristic impedances of rectangular and circular waveguides for fundamental modes", IEEE 3rd Ukraine Conference on Electrical and Computer Engineering, Lviv, Ukraine, August 2021, pp. 46-51.

[96] A. Polishchuk et al., "Compact posts-based waveguide polarizer for satellite communications and radar systems", IEEE 3rd Ukraine Conference on Electrical and Computer Engineering, Lviv, Ukraine, August 2021, pp. 78-83. 